\title{
GUITARRA FLAMENCA SP. NOV. (PORIFERA: POECILOSCLERIDA) WITH A SEM REVISION OF THE SPINY ISOCHELAE AND PLACOCHELAE IN THE GENUS
}

\author{
J.L. CARBALLO* AND $\mathrm{M}^{\mathrm{a}}$.J. URIZ \\ *Laboratorio de Biología Marina, Facultad de Biología, Universidad de Sevilla, Ap. 1095, 41080-Sevilla, \\ Spain. ${ }^{\dagger}$ Centro de Estudios Avanzados de Blanes, CSIC Camí de Santa Bárbara, 17300 Blanes, Girona, Spain
}

All the currently known species of Guitarra with spiny isochelae have been reviewed by SEM: Guitarra fimbriata, Guitarra indica, Guitarra bipocillifea, Guitarra abbotti and Guitarra laplani. A new species from Namibia; Guitarra flamenca, is described, which is characterized by bipocilla-like spiny isochelae similar to those of Tetrapocillon atlanticus, placochelae in two different morphological categories and very robust megascleres. After a revision through SEM of the specimen of Guitarra fimbriata var. indica, it clearly belongs to Guitarra flamenca sp. nov. The morphological variability of the placochelae and the spiny isochelae across the Guitarra-species has been analysed and the main parameters useful to differentiate species are highlighted.

\section{INTRODUCTION}

The genus Guitarra was erected by Carter (1874) to include a sponge (G. fimbriata) with a very characteristic spicule type, named placochelae, in the shape of a Spanish guitar or an hourglass. The first diagnosis of this genus described the placochelae as the only microsclere present since the spiny isochelae were disregarded by Carter due to their small size. Other species of Guitarra were later described based on the presence of microscleres other than placochelae, such as sigmas (G. antarctica Hentschel, 1914 and G. sigmatifera Topsent, 1916) 'bipocilla' (G. bipocillifera Brøndsted, 1924), spiny isochelae (G. indica Dendy, 1916) or even because of the absence of spiny isochelae (e.g. G. voluta Topsent, 1904). In 1929, however, Burton put in synonymy the six species of Guitarra described up to that time with Guitarra fimbriata. Thus, this species was supposed to be cosmopolite and to display a noticeable skeletal plasticity. Burton's (1929) opinion was followed by most contemporaneous authors who ascribed the observed differences to local variability (e.g. Lévi, 1963).

Most recently, Lee (1987) after examining the holotypes of G. fimbriata, G. sigmatifera and $G$. antarctica through scanning electron microscopy (SEM), concluded that, according to the spicule variation found, the three species were clearly different. Moreover, in contrast to Burton's opinion, Lee (1987) showed that intraspecific variability was low in those species. He also attributed the previously assumed plasticity to a mere misinterpretation of the microsclere differences: slight, at first sight, under the optic microscope but noticeable under SEM. Scanning electron 
microscopy observation of the microscleres called up to that time bipocilla showed these spicules to be spiny isochelae or isochelae derived forms, with no relation to true bipocilla.

Furthermore, Lee (1987) described two new species of Guitarra (viz. G. abbotti and G. isabellae) which had placochelae in two clearly distinct size-classes, as well as a new spicule type previously unknown in living forms, named biplacochelae. These two new species clearly differ from each other in the form of the spiny isochelae and in the presence or absence of sigmas, respectively.

Most recently, Boury-Esnault et al. (1993) re-examined the holotype of G. fimbriata and provided the first SEM photographs of its spiny isochelae which allowed them to state that the specimens from New Zealand described as G. fimbriata by Bergquist \& Fromont (1988) actually belong to G. bipocillifera. In the same study, these authors described a new Guitarra species, G. laplani, which had the spiny isochelae completely different from those of any species previously known and also discussed the cosmopolitan character of G. fimbriata.

The species diagnostic characters have been explored by SEM observation of the microscleres (placochelae and spiny isochelae). Scanning electron microscopy observation of these microscleres has proved to be very useful in distinguishing close species of Guitarra (Lee, 1987; Boury-Esnault et al., 1993).

This study pursues clarifying the differences between the known species of Guitarra, some of them still regarded as $G$. fimbriata by recent authors (i.e. Hooper \& Wiedenmayer, 1994) by examining their microscleres through the scanning electron microscope. This has allowed us to identify a new species of this genus.

\section{MATERIALS AND METHODS}

The specimens of the new species were collected by SCUBA diving and then were preserved in $70 \%$ alcohol. Preparation of dissociated spicules for electron microscopy (SEM) followed the techniques described by Rützler (1974). The pictures of microscleres were taken through a scanning electron microscope PHILIPS XL 20 by previously clearing, dehydrating, and coating the spicules with gold.

The spicule measurements between parentheses in the species descriptions correspond to average values. A frequency histogram of the length of the placoquelae was plotted for studying the size-classes in Guitarra flamenca sp. nov. $(\mathrm{N}=100$, bimodal).

The holotype of Guitarra flamenca sp. nov. together with a SEM preparation have been deposited in the Museo Nacional de Ciencias Naturales de Madrid, MNCN (Spain) under the reference number cited in the species description.

Duplicate preparations of spicules and a piece of the holotype have been deposited in the Laboratorio de Biología Marina of the Universidad de Sevilla with reference no. LBM-01/12/95-1/030. 


\author{
RESULTS \\ SYSTEMATICS \\ Order Poecilosclerida \\ Family Guitarridae Gray, 1867 \\ Genus Guitarra Carter, 1874
}

\title{
Diagnosis
}

Guitarridae in which the choanosomal skeleton consists of a reticulation of oxeas or styles. Brushes of megascleres are present at the sponge surface. Megascleres of one size category. The characteristic microscleres are placochelae, sometimes together with biplacochelae, which may be accompanied by spiny isochelae or isochelae-like spicules, and sigmata. Aquiferous orifices clustered in papillae-like areas (slightly modified from Lee, 1987).

Guitarra flamenca sp. nov.

Guitarra fimbriata var. indica Lévi, 1963

\section{Diagnosis}

Guitarra with fusiform and flexuous styles as megascleres, placochelae in two size classes, the large ones with a very marked central constriction, a pellucid area hexagonal in shape, and a discontinuous fringed border. With bipocilla-like spiny isochelae.

\section{Material examined}

Holotype MCNM (Madrid) 1.01/177, Shark Island, Lüderitz (Namibia), $5 \mathrm{~m}$, 1 December 1995, small overhang. Specimen of Guitarra fimbriata var. indica from South Africa (Lévi, 1963) (MNHN, LBIM no. CL440).

\section{Description}

Encrusting specimen of about $1.5 \mathrm{~cm}$ in thickness, covering an area of $8 \times 4.7 \mathrm{~cm}$. The surface is mostly even, except for some zones with slightly elevated protuberances probably bearing the aquiferous orifices although this could not be confirmed because it was contracted. Ectosome dark brown, and choanosome light brown in colour. The surface is smooth to the touch but minutely hispid under the stereo microscope. However, some areas also appear microscopically smooth as well. The consistency is compressible like that of a keratose sponge. The ectosome, $0.51 \mathrm{~mm}$ in thickness, is not detachable from the choanosome. The specimen, collected during the austral spring, incubated embryos.

\section{Skeletal arrangement}

In the ectosome, the megascleres form brushes $100-120 \mu \mathrm{m}$ in diameter at the base and $250-360 \mu \mathrm{m}$ at the end. These brushes are placed perpendicular to the sponge surface barely protruding to the exterior. In the choanosome, bundles of $100-210 \mu \mathrm{m}$ in thickness form a fairly regular isotropic reticulation. These bundles delimit rounded 
or oval spaces $100-1200 \mu \mathrm{m}$ wide which contain the embryos. Single megascleres are also scattered throughout the choanosome. The network takes on a more confused configuration near the ectosome. Microscleres are widespread throughout the sponge.

Spicules

Fusiform and flexuous styles (Figure 1). Frequently undulating, with one acerate and, sometimes, lanceolate extremity. Occasionally, they present a central swelling. Measurement (mean in parentheses): 252-(312)-380 ×6(12)-18 $\mu \mathrm{m}$.

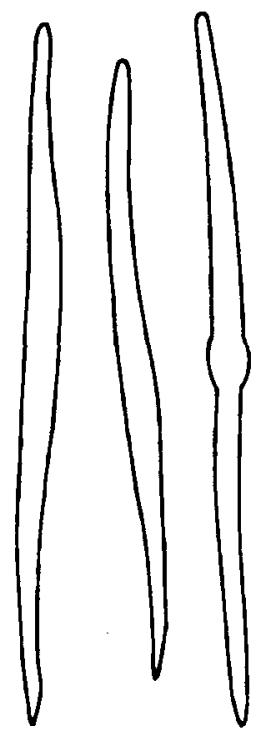

Figure 1. Megascleres of Guitarra flamenca sp. nov.

Placochelae: of two size-classes displaying a somewhat different morphology (Figure 2). The larger placochelae have a discontinuous fringed border. The pellucid area is hexagonal in shape, becomes narrower at the spicule centre, and has a deep central constriction. The plate end is circular in shape. Measurements: shaft length: 74.4$95 \mu \mathrm{m}$; width in the waist: $16 \cdot 8-22.5 \mu \mathrm{m}$. The smaller placochelae have a discontinuous fringed border (Figure 2D), which progressively becomes narrower towards the spicule centre, and the pellucid area is hexagonal in shape. The plate end is slightly oval. Some of the placochelae II of the paratype display a small neck in the central part (Figure 3A). Measurements: shaft length: $3150 \mathrm{~mm}$; width in the waist: $4.2-8.7 \mu \mathrm{m}$. The larger placochelae are scarce in the paratype.

Spiny isochelae (Figures 2, 3 and 5). Of the bipocilla-like form, with a relatively long and thin shaft and the alae fused in the form of a hemispheric cup. Spines clustered in groups covering both the alae and shaft. Length: 11-18.5 $\mu \mathrm{m}$. 


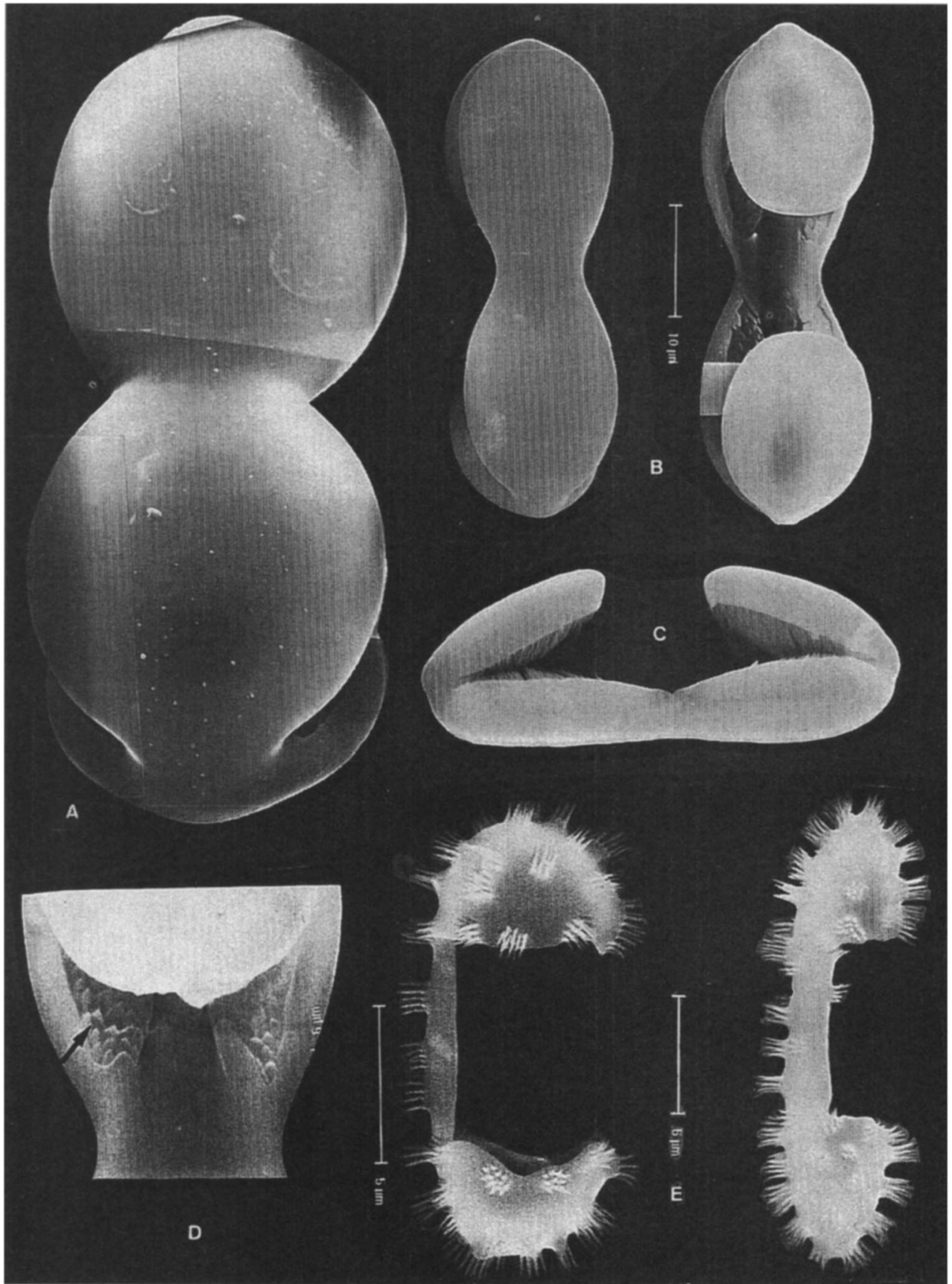

Figure 2. Holotype of Guitarra flamenca sp. nov.: (A) placochelae I; (B) placochelae II; (C) lateral view of a placochelae I; (D) detail of the fringed border placochelae II; (E) spiny isochelae. 


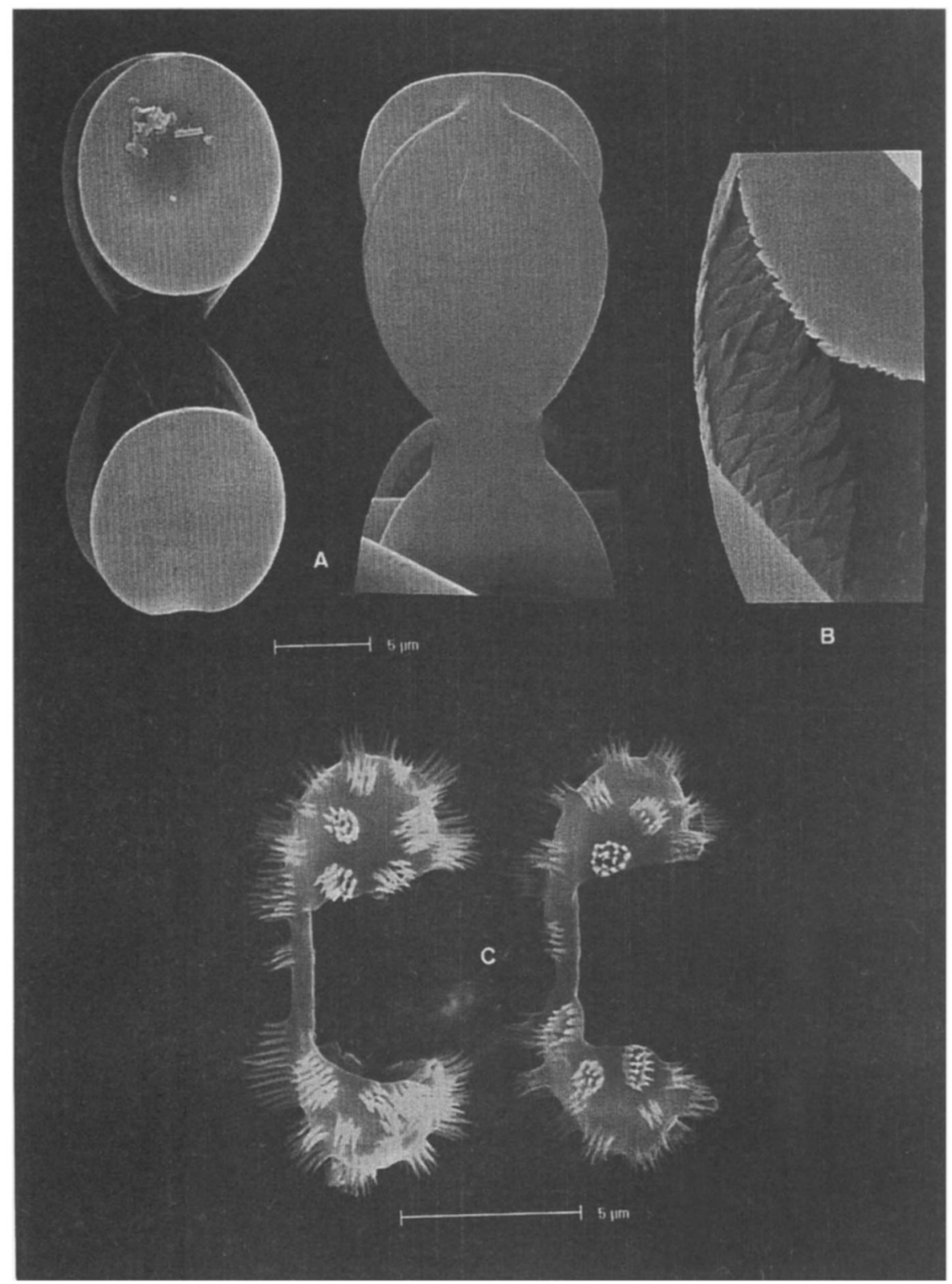

Figure 3. Paratype of Guitarra flamenca sp. nov.: (A) placochelae II; (B) detail of the fringed border; (C) spiny isochelae.

Rounded silica formations with diverse lobes are frequent (Figure 4). Measurements: $35-82 \mu \mathrm{m}$ at its greatest diameter. These forms are common in sponges dwelling in silica rich environments such as in the upwelling regions of Namibia were the species lived. These silica formations only have been found in the holotype. 


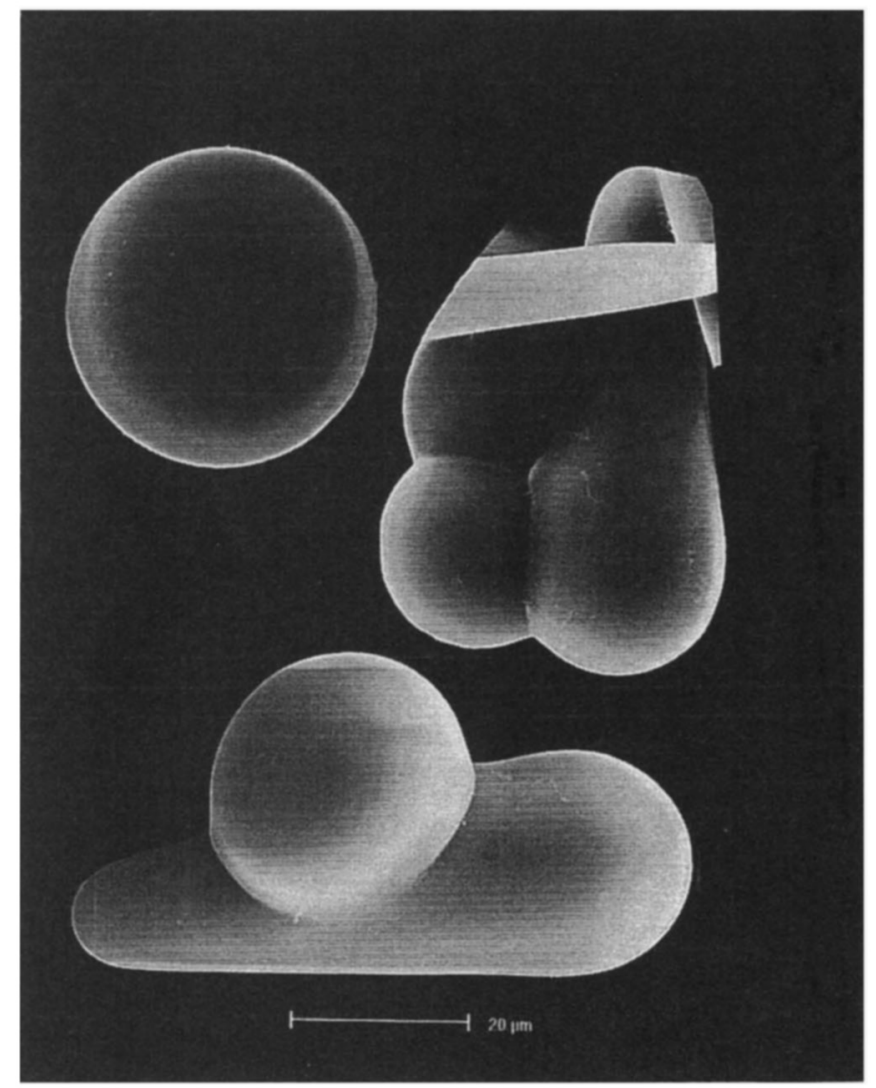

Figure 4. Aberrant silica formations in Guitarra flamenca sp. nov.

\section{Remarks}

The new species Guitarra flamenca is distinguished from all other Guitarra species by having a peculiar bipocilla-like spiny isochela, placochelae in two different size and form-classes, and very robust megascleres. Its closest relative seems to be Guitarra abbotti Lee, 1987, from which it, differs, however, in the presence in the latter species of biplacochelae. Furthermore, the form of the spiny isochelae and the megascleres are also very different in both species. The shaft of the isochelae in G. abbotti (Figure 5F) is much shorter (sometimes even absent) than in those of G. flamenca (Figure 5D). It also differs from the remaining Guitarra species with spiny isochelae because of the particular morphology of its larger placochelae, which only resemble those of G. indica, and because of the two different morphological categories of its placochelae. Moreover, the shape of the megascleres characterizes the species, thus also separating it from G. fimbriata and G. bipocillifera (with oxeas) and G. laplani (with styles). 


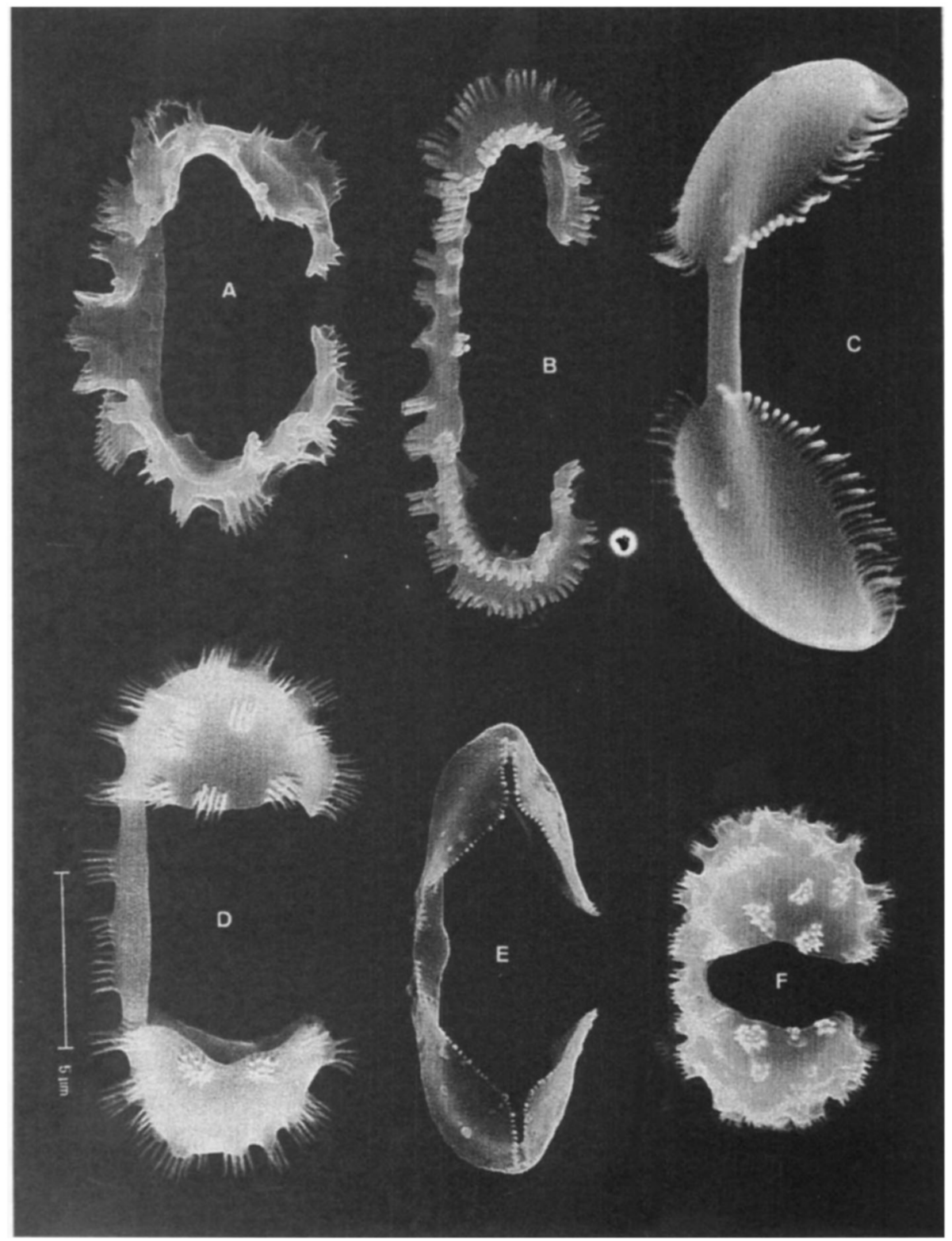

Figure 5. Spiny isochelae of different species of Guitarra: (A) G. fimbriata; (B) G. indica; (C) G. bipocillifera; (D) G. flamenca sp.nov; (E) G. laplani; (F) G. abbotti.

\section{Habitat}

The only specimen collected dwelled on a small cornice with high levels of sedimentation in the Laminaria sp. assemblage. The species is in reproduction during October. The different specimens collected by Lévi and described as G. fimbriata var. indica were collected in sand, rocks, stones, shell, etc. between 10 and $14 \mathrm{~m}$ in depth. 


\section{Etymology}

The species name refers to the particular Spanish guitar used to play 'flamenco', a folk sound from the south of Spain.

\section{DISCUSSION}

In the genus Guitarra, four different types of microscleres have been found to date: placochelae, biplacochelae, sigmas and isochelae. The morphology of the isochelae and placochelae have been studied through SEM analysis, and the main characteristics have been evaluated from a taxonomic point of view in order to discriminate between species.

The spiny isochelae display completely different morphologies which characterize some species of Guitarra. According to the SEM studies, there are four distinguishable types of spiny isochelae: sigmoid, bipocilla-like, palmate and spoon-like (Figure 5). The sigmoid form is a highly modified isochelae, with laterally reduced alae and the spines clustered in groups rising from the entire surface. This type is found in the species G. fimbriata and G. indica. The bipocilla-like shape is characterized by cupshaped fused alae. Their spines are also clustered forming groups and in the sigmoid type. It is typical of the species G. abbotti and G. flamenca sp. nov. The palmate isochelae, with separate alae and the spines arranged in a row along the spicule border, characterizes the species G. laplani. A simplification of this form by fusion and reduction of the alae is the spoon-like type present in G. bipocillifera.

\section{Isochelae-type microscleres}

Spiny sigmoid isochelae. They are abundantly spiny isochelae with very reduced alae. The spines can be stout as in G. fimbriata, or much more slender as in G. indica. In G. indica the alae are much more separated from each other than in G. fimbriata, thus giving them a much more sigmoid-like aspect (Figure $5 \mathrm{~A}, \mathrm{~B}$ ).

Spiny isochelae with a characteristic spoon-like shape. The spines are arranged in a row around the alae's border. They are absent from the shaft. These spicules are small slender bipocilli, but have small rounded caps at each end oriented at an acute angle to the shaft (Figure 5C) (G. bipocillifera).

Bipocilla-type isochelae. Spicule with a relatively long and thin shaft (in G. abbotti it is much shorter than in $G$. flamenca) and the alae are fused in the form of a hemispheric cup. Spines are clustered in groups covering both the alae and the shaft (Figure 5D,F).

Spiny palmate isochelae. Isochelae with spines forming a row along the spicule border and with alae that do not join together (Figure 5E) (G. laplani). 
After studying the placochelae of six different Guitarra species through the electron and light microscopes, we can conclude that, of the various structures or parts in a placochela recognized by Lee (1987), the most significant features are: the shape of the central pellucid area which is related to the form of the fringed border, and the spicule outline. Both characters are closely related to each other. The placochelae with a slight central constriction have a continuous fringed border and the pellucid area is rhomboid in shape. In contrast, those placochelae with a well defined constriction always have a discontinuous fringed border and the pellucid area is hexagonal in shape. The placochelae of the species G. fimbriata, G. abbotti, G. isabellae and G. laplani are characterized by a rhomboid central pellucid area, in contrast to the hexagonal shape found in the species G. indica and G. flamenca sp. nov. Again, in the latter group, the fringed border is interrupted in the centre of the placochela whereas, in the first group, the border is continuous along the spicule length although slender in the central area. These differences are apparent through both the optical and electronic microscopes, although SEM is recommended, especially when the presence of a new species is suspected, as for other sponge genera with very small skeletal elements (Carballo \& García-Gómez, 1994).

With regard to the placochela dorsal view, the typical guitar shape with a conspicuous central narrowing produced by a sharp decrease in the diameter from the extremes towards the central area (Figure $6 \mathrm{C}$ ) only appears in the species $\mathrm{G}$. indica and

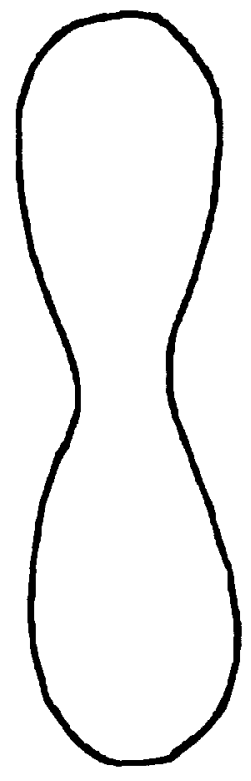

A

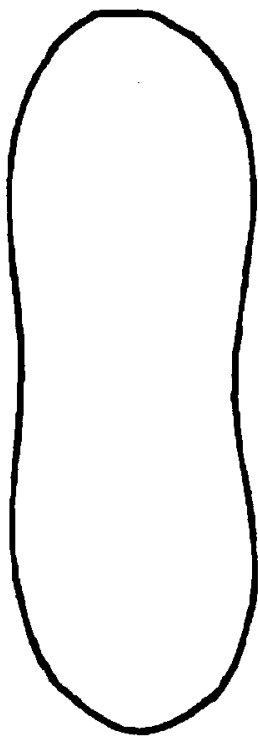

B


Figure 6. Characteristic outlines of the main types of placochelae: (A) fimbriata-type outline; (B) laplani-type outline; (C) flamenca-type outline. 
G. flamenca. A variation of this type, present in some spicules of G. flamenca, is represented by forms with a small neck clearly separating the two rounded parts of the placochela (Figure 3A). The opposite case is represented by those spicules almost rectangular in shape, where the central constriction is hardly distinguishable (Figure 6B). They are typical of the species G. abbotti, G. laplani, etc. Finally, the spicules of G. fimbriata are halfway between the other two in shape (Figure 6A).

\section{Outline of placochelae}

Three main types of outlines have been found: (i) fimbriata type outline (Figure 6A): placochelae with a progressive reduction in the diameter from the ends towards the waist (G. fimbriata and G. bipocillifera). (ii) Laplani type outline (Figure 6B): placochelae with a slightly-defined waist. The spicule outline is very characteristic, without a conspicuous waist (G. laplani and G. abbotti). (iii) Flamenca type outline (Figure 6C): placochelae with a very marked central constriction. The shaft is very abruptly constricted in the middle (G. flamenca and G. indica).



A

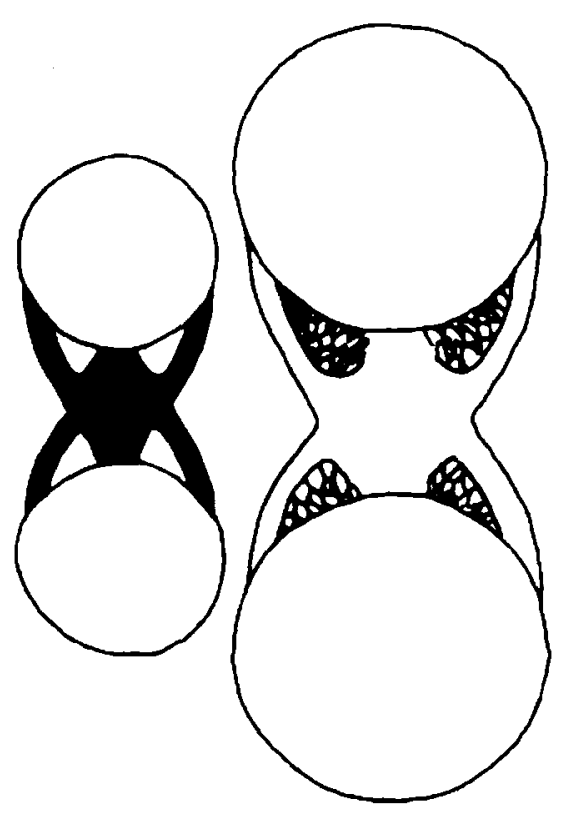

B

Figure 7. Drawing of the two main types of placochelae: (A) with a slightly-defined waist, with the central pellucid area in a broad rhomboid shape and a continuous fringed border; (B) with a very marked central constriction, a pellucid area hexagonal in shape, and a discontinuous fringed border. 


\section{Shape of the central pellucid area of the placochelae:}

Two types have been found: (i) with the central pellucid area in a broad rhomboidshape. When the central pellucid area is rhomboid in shape the border fringe is continuous along the entire shaft (Figure 7A) (G. fimbriata, G. bipocillifera, G. abbotti and G. laplani). (ii) With the central pellucid area hexagonal in shape. In this case the placochelae always have a discontinuous fringed border (Figure 7B) (G. flamenca and G. indica).

Another interesting characteristic for distinguishing among close species of Guitarra may be the number of categories of the placochelae. However, the extent of this character is difficult to evaluate in this study since not all the type material has been re-examined yet.

\section{KEY OF GUITARRA SPECIES}

1. Biplacochelae present. . . . . . . . . . . . . . . . . . . . . . . 2

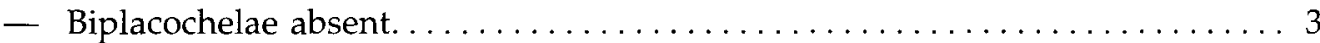

2. With bipocilla ............................. G. abbotti

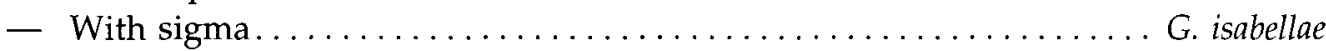

3. The large placochelae with pellucid area hexagonal in shape, and with a discontinuous fringed border $\ldots \ldots \ldots \ldots \ldots \ldots \ldots \ldots \ldots \ldots$

- The central pellucid area in a broad rhomboid shape and a



4. Placochelae with a very marked central constriction. With bipocilla-like spiny isochelae G. flamenca

- Placochelae with a marked central constriction. With sigmoid spiny isochelae $\ldots \ldots \ldots \ldots \ldots \ldots \ldots \ldots \ldots \ldots \ldots \ldots \ldots \ldots \ldots \ldots \ldots \ldots \ldots \ldots$

5. With only placochelae. Megascleres monactines .............. G. voluta

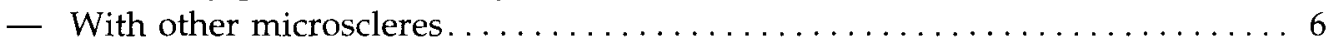

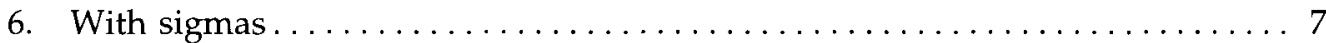

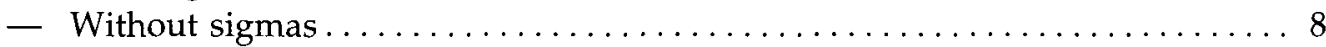

7. With monactine megascleres $\ldots \ldots \ldots \ldots \ldots \ldots \ldots \ldots \ldots \ldots$. sigmatifera

- With diactine megascleres. ...................... antarctica

8. Placochelae with a progressive reduction in the diameter from the ends towards the waist. Megascleres are oxeas. .............. 9

- Placochelae with a slightly conspicuous central constriction. Megascleres are styles. With palmate spiny isochelae .......... G. laplani

9. Supplementary microscleres are sigmoid spiny isochelae ........ G. fimbriata

- Supplementary microscleres are isochelae with spoon like alae

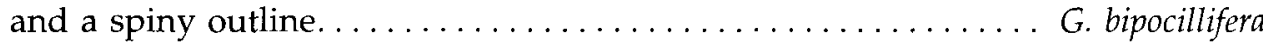


J.L.C. would like to thank the Ministry of Fisheries and Marine Resources of the Republic of Namibia for the facilities made available, as well as Miss B. Curry and K. Grobler from the Fisheries Centre of the Republic of Namibia for their help in the scientific expedition where the species Guitarra flamenca was collected. Part of this study was carried out under a R+D postdoctoral grant awarded by the DGICYT of the Spanish Ministry of Culture and Education in collaboration with Pharma-Mar company. Thanks to Alma Velasco for the English revisions. We also thank C. Valentine for providing us with the holotypes of $G$. fimbriata and G. indica, T. Gosliner and the Academy of Sciences for the paratype of G. abbotti; C. Lévi for the loan of one specimen of Guitarra fimbriata var. indica from South Africa and the holotype of G. laplani, and to P. Bergquist for the SEM photograph of the microsclere of G. bipocillifera. M.J.U. acknowledges funding by the project MAR95-1764 and the support of the Government of Catalonia (1995SGR 00443).

\section{REFERENCES}

Bergquist, P.R. \& Fromont, P.J., 1988. The marine fauna of New Zealand: Porifera, Demospongiae, Part 4 (Poecilosclerida). Memoirs. New Zealand Oceanographic Institute, no. 96.

Boury-Esnault, N., Pansini, M. \& Uriz, M.J., 1993. Cosmopolitism in sponges: the 'complex' Guitarra fimbriata with description of a new species of Guitarra from the northeast Atlantic. Scientia Marina, 57, 367-373.

Brøndsted, H.V., 1924. Sponges from New Zealand. Part I. Papers from Dr Th. Mortenseńs Pacific Expedition 1914-16. XXIII. Videnskabelige Meddelelser fra Dansk Naturhistorisk Forening $i$ Kjøbenhavn, 77, 435-483.

Burton, M., 1929. Porifera. Part 2. Antarctic sponges. British Antarctic 'Terra Nova' Expedition, 1910. Report. British Museum (Natural History) (Zoology), 6, 393-458.

Carballo, J.L. \& Garcia-Gómez, J.C., 1994. The northeastern Atlantic species Mycale micracanthoxea Buiser \& Van Soest, 1977 (Porifera, Poecilosclerida) in the Strait of Gibraltar (southern Spain). Beaufortia, 44, 11-16.

Carter, H.J., 1874. Descriptions and figures of deep-sea sponges and their spicules from the Atlantic Ocean dredged up on board II.M.D. 'Porcupine', etc. Annals and Magazine of Natural History, 14, 207-221.

Dendy, A., 1916. Report on the non-calcareous sponges collected by Mr James Hornell at Okhamandal in Kattiawar in 1905-6. Report to the Government of Baroda on the Marine Zoology of Okhamandal in Kattiawar. Part 2, pp. 95-146.

Hentschel, E., 1914. Monaxone Kieselschwämme und Hornschwämme der Deutschen SüdpolaExpedition 1901-1903. In Deutsche Südpolar-Expedition 1901-1903, vol. 15 (Zoologie 7) (ed. E. von Drygalski), pp. 35-142. Berlin: Publishers.

Hooper, J.N.A. \& Wiedenmayer, F., 1994. Porifera. Zoological Catalogue of Australia. Vol 12. Melbourne, Australia: CSIRO.

Lee, W.L., 1987. Guitarra abbotti and G. isabellae, new sponges from the Eastern Pacific. Proceedings of the Biological Society of Washington, 100, 465-479.

Lévi, C., 1963. Spongiaires d'Afrique du sud. I. Poecilosclerides. Transactions of the Royal Society of South Africa, 37, 1-72.

Rützler, K., 1974. The burrowing sponges of Bermuda. Smithsonian Contributions to Zoology, no. $165,1-32$.

Topsent, E., 1904. Spongiaires des Açores. Résultats des Campagnes Scientifiques accompliés par le Prince Albert I Monaco, 25, 1-280.

Topsent, E., 1916. Diagnoses dÉponges recueillies dans l'Antarctique par la Pourquoi-Pas? Bulletin du Muséum National d'Histoire Naturelle, 3, 163-172. 